\title{
Results of theoretical and experimental studies on determining the coefficient of subgrade reaction of sleepers for the conditions of main railways with axial loads of $30-35$ tons per axle
}

\author{
Oleksandr Darenskiy ${ }^{1,}$, Eduard Bielikov ${ }^{1}$, Olexii Dudin ${ }^{1}$, Alina Zvierieva ${ }^{1}$, and Anatolii \\ Oleshchenko ${ }^{2}$ \\ ${ }^{1}$ Ukrainian State University of Railway Transport, 61050, Feierbakh Square 7, Kharkiv, Ukraine \\ ${ }^{2}$ National Academy of the National Guard of Ukraine, Defenders of Ukraine Square 3, 61001, \\ Kharkiv, Ukraine
}

\begin{abstract}
The article considers obtaining numerical values of the coefficient of subgrade reaction of wooden and reinforced concrete sleepers with axial loads up to 30-35 tons per axle. It has been concluded that using the rolling stock with axial loads of up to 35 tons per axle is necessary in order to ensure sustainable development of the railway complex. The performance of the railway track thus should be investigated in order to predict its operation in such conditions. Generally, such studies are performed using numerical methods. One of the parameters that are required for such calculations is the parameter which is commonly called the coefficient of subgrade reaction. Empirical dependencies of the coefficient of subgrade reaction of wooden and reinforced concrete sleepers on the axial load and on the operating conditions of the track have been obtained. The obtained results can be used in studies of the interaction dynamics of the track of main railways with rolling stock with axial loads of 30-35 tons per axle, which will give an opportunity to provide well-grounded recommendations on the rules for the arrangement and maintenance of the track in such conditions.
\end{abstract}

\section{Introduction}

An increase in grain exports is the routine issue of the Ukrainian economy. Thus, despite logistical difficulties, 19.7 million tons of grain was exported by December 13, 2016, which is almost one million tons more than in 2015. However, maintaining such transportation volume becomes more difficult every year. About one thousand cars have been decommissioned (in 2011, the railways managed to dispatch 2,500 cars a day vs. about 2,100 cars per day now. The main factor of reduction is the physical wear of the fleet of grain hoppers, which in turn reduces the speed of railway operations and prevents from loading cars at full capacity). The number of available road vehicles is decreasing, as the

* Corresponding author: ppx_xiit@kart.edu.ua 
fleet of vehicles is not renewed. Launching an automated car distribution system, which will also include grain hoppers, as well as an increase in axial load from 23.5 tons to 30-35 tons will help solve the problem.

The existing methods of calculating the effect of the rolling stock with such loads on the track cannot give an unambiguous answer to the question how the relationship of the track and rolling stock will change with such cars, how the dynamic interaction will change and how it will affect the performance of the track. Only dynamic calculation of the interaction forces between the track and the rolling stock can give the answer, for example, using the mathematical model of the 3D and dynamic system "vehicle-track" developed by A. M. Darenskiy [1].

One of the characteristics required for such calculations is the coefficient of subgrade reaction, which as shown by [1], depends on the load on the support, and, finally, on the value of the axial load. Thus, studying this parameter becomes a relevant task.

In the leading domestic and foreign studies, which will be outlined below, the coefficient of subgrade reaction is determined by experimental methods. Since in the global practice, the axial loads of 30-35 tons per axle are not used on main railways, the studies carried out by the authors for the conditions of non-public railways in conditions that are identical to those of the main lines were accepted as the basis.

\section{The analysis of studies and publications}

The effect of elastic properties of sleepers and their base on the formation of vertical stiffness of the track is very significant, which is noted by many researchers. For example, the calculations performed in [2] showed that the proportion of this parameter in the formation of the elastic modulus of the track with wooden sleepers in the summer is $77 \%$ to $90 \%$. The experiments conducted at the German railways [3] determined that the specific weight of sleepers and their bases in the total vertical deformation of the track is $80 \%$ for wooden sleepers, and $95 \%$ for reinforced concrete sleepers.

It is noted that the stiffness of the track (taking into account the bending stiffness of the rails) and the stiffness of the rail supports depend essentially on the type of sleepers (wooden or reinforced concrete ones) and on the type of liners used in intermediate fastenings $[4,5,6,7]$. In winter, when the ballast and roadbed are frozen, the stiffness of the track increases 1.5 times [7], and according to other data, even 2-3 times [4].

The elastic component of the displacement resistance forces of sleepers in the vertical plane is now assumed to be defined as:

$$
R_{y}=C_{y u} \cdot y_{p}=C_{y \sigma} \cdot \alpha \cdot \Omega_{u} \cdot y_{p},(\mathrm{kN})
$$

where $C_{y u}$ - element of the vertical stiffness of the rail support, depending on elastic properties of the sleeper at bends under the action of vertical forces and elastic properties of the ballast layer and roadbed $(\mathrm{kN} / \mathrm{m}) ; y_{p}$ - vertical displacements of a sleeper in the subrail section under the action of force $R_{y}(\mathrm{~m}) ; C_{y \sigma}$ - coefficient of subgrade reaction $\left(\mathrm{kN} / \mathrm{m}^{3}\right) ; \alpha$ - bending coefficient of a sleeper; $\Omega_{\mathrm{II}}$ - area of a half-ties $\left(\mathrm{m}^{2}\right)$.

Many experiments [8-10, etc.] were devoted to the experimental determination of the values of the coefficient of subgrade reaction. Basically, values of $C_{y \sigma}$ parameter are given for static loading of the track, since the methods for determining the dynamic stiffness are still neither well investigated nor defined. For example, methods for determining the dynamic parameters proposed in [9] are known. It is noted that in case of dynamic loads, the value of the coefficient of subgrade reaction can be $70 \%$, and in some cases $-60 \%$, of this value at static loading. Theoretical substantiation of this phenomenon as a result of ballast vibration is given in [5]. 
In the process of operation, as the ballast is compacted and contaminated, the coefficient of subgrade reaction of the sleepers increases by $40-80 \%$ [11].

For the conditions of main railways with loads up to 25 tons per axle, the value of the coefficient of subgrade reaction of wooden sleepers is recommended to be assumed in the range from 65 to $85 \mathrm{mPa} / \mathrm{m}$ for the summer and from 120 to $180 \mathrm{mPa} / \mathrm{m}$ for the winter conditions $6.5-8.5 \cdot 10^{-4}$ and $12-18 \cdot 10^{-4} \mathrm{kN} / \mathrm{m}^{3}$. In case of reinforced concrete sleepers, the coefficient of subgrade reaction is $[4,9,11] 180-240 \mathrm{mPa} / \mathrm{m}$ for the summer and $280-340$ $\mathrm{mPa} / \mathrm{m}$ for the winter conditions. Since there is no experience of operation of the rolling stock with high axial loads on main lines, the experience of operation of access ways should be used. For industrial railways, this issue requires special research.

\section{The basic part}

The coefficients of subgrade reaction of sleepers for the conditions of the railways of the Ukrainian industrial enterprises have been determined on the basis of the data of experimental studies conducted in 2010-2012.

The works were carried out at 21 sections of the track of metallurgical and mining enterprises. The studied sections were selected on the internal connecting and access roads of enterprises with the upper track structure on the reinforced (fastening KB) and wooden (fastening DO) sleepers.

At each investigated section, 3 to 5 sleepers were tested. Vertical loads on the sleepers from the rolling stock were recorded using dynamometric substrates, vertical displacement of sleepers were recorded using a digital video displacement metering system [12]. Vertical forces and displacements of sleepers were recorded continuously in digital form in the computer memory during the passing of the train.

The recorded information was copied and sent to MS Excel spreadsheet. Charts of elastic characteristics of sleepers for the mean values of displacements and loads for each section were constructed on the basis of these data. Elastic characteristics for both reinforced concrete and wooden sleepers are fading (rigid), and the vertical stiffness of sleepers increases with increasing loads (Fig. 1, Fig 2).

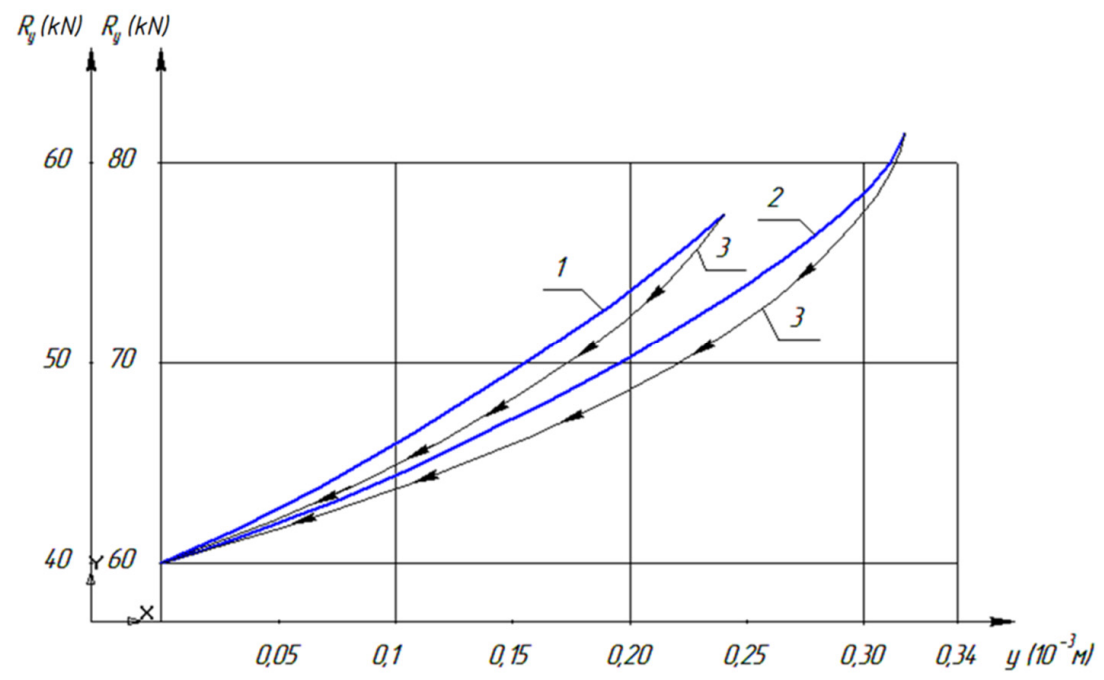

Fig. 1. Elastic characteristics of reinforced sleepers under vertical loads: 1 - section 14, hot-metal car $80 \mathrm{t}, P o c=353 \mathrm{kN} / \mathrm{axle}$, service life of the track -5 years, tonnage -60 million tons; 2 - section 19 , dump car 6-BC-60, Poc $=215 \mathrm{kN} / \mathrm{axle}$, service life of the track -5 years, tonnage -90 million tons; 3 - elastic characteristics at unloading 


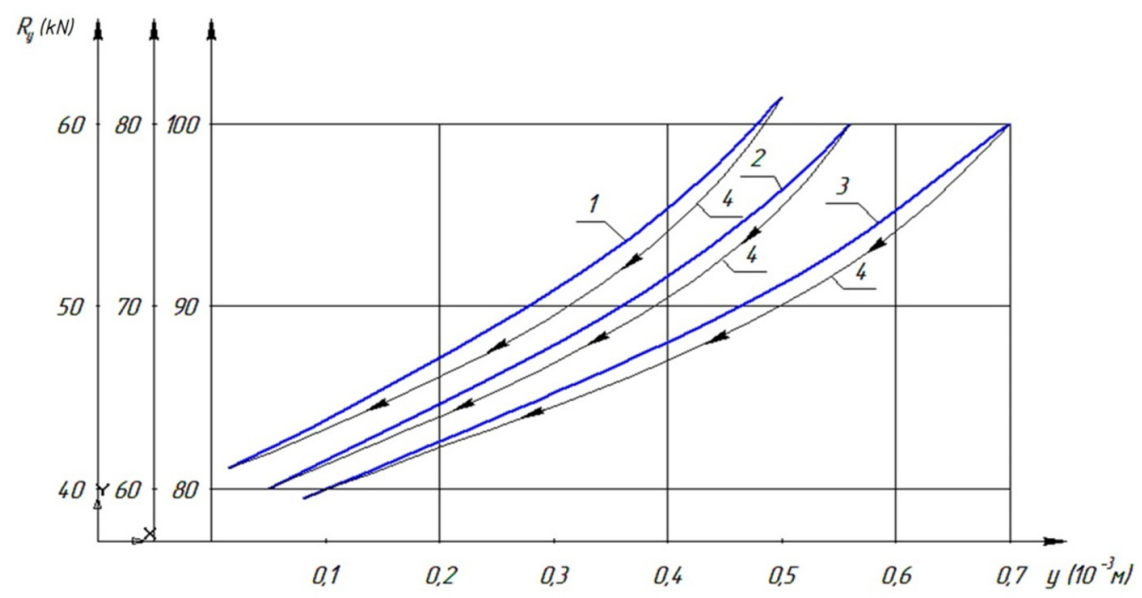

Fig. 2. Elastic characteristics of wooden sleepers under vertical loads: 1 - section 7, casting form bogies I-120-5500, Poc $=35.25 \mathrm{t} / \mathrm{axle}$, service life of the track -6 years, tonnage -48 million tons; 2 - section 10, platform of hot-metal car $70 \mathrm{t}, P o c=245 \mathrm{kH} /$ axle, service life of the track 12 years, tonnage -49 million tons; 3 - section 2, hot-metal car 50t, $P o c=201 \mathrm{kN}$, service life of the track 7 years, tonnage -50 million tons; 4 - elastic characteristics at unloading.

The stiffness of sleepers at vertical loads of a single rail line has been determined by linearizing the elastic characteristics using the chord method for the ranges 40-60, 60-80 and $80-100 \mathrm{kN}$, which corresponds to the actual loading on the sleepers when trains with axial loads up to $265 \mathrm{kN}, 265$ to 294 and more than $294 \mathrm{kN}$ per axle move.

The obtained information suggests that the vertical stiffness of reinforced sleepers increases with the increase of operating load ranges with the comparable values of the tonnage passing the sections. This increase is $31-37 \%$ in the ranges $60-80 \mathrm{kN}$ vs. the range $40-60 \mathrm{kN}$. For wooden sleepers this increase is from $22-27 \%$ to $52-59 \%$ (Fig. 1, Fig. 2) for different types of cars.

An increase in vertical stiffness was recorded for sections where identical rolling stock moves and which differ in terms of service life of the track. For example, Fig. 3 contains the values of the stiffness of reinforced concrete and wooden sleepers (single-rail line) obtained for the sections of loaded dump cars 6-BC-60 with permitted axial loads up to $216 \mathrm{kN} / \mathrm{axle}$, with the service life of the track of up to 18 years, and the passing tonnage from 0 to 180 million tons.

It can be assumed, and this assumption is confirmed by the experiments, that it is the tonnage passing the sections as a generalizing factor of force impact on the track that has a determining influence on the change in the stiffness of sleepers under vertical loads and on the coefficient of subgrade reaction of sleepers. As the tonnage increases, density and contamination of the ballast also increase, which causes an increase in the stiffness of sleepers.

Coefficient of subgrade reaction of reinforced concrete and wooden sleepers was determined using the investigated data as

$$
C_{y \sigma}=\frac{R_{y}}{\alpha \cdot \Omega_{u} y_{p}}
$$

where $R_{y}$ - vertical load effecting the sleeper $(\mathrm{kN}) ; \Omega_{\mathrm{m}}$ - area of half-ties $\left(\mathrm{m}^{2}\right) ; y_{p}$ - vertical displacements of the sleeper in the subrail section $(\mathrm{m}) ; \alpha-$ bending coefficient of the sleeper. 


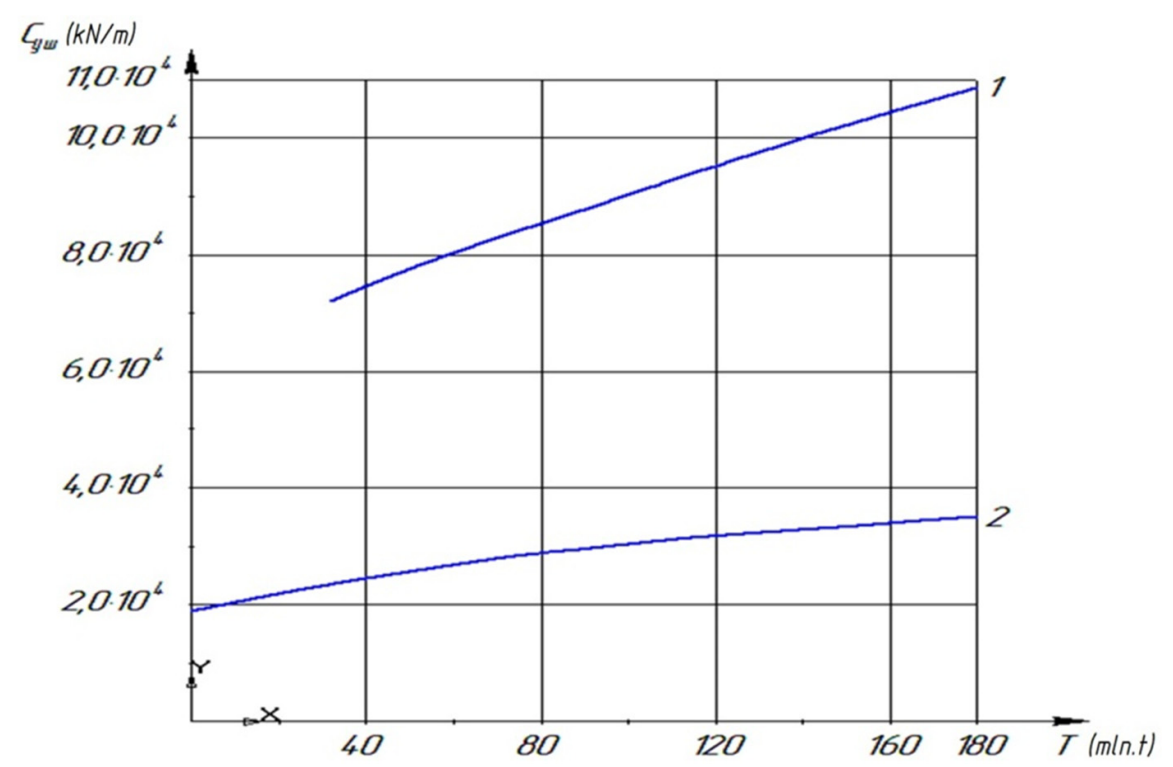

Fig. 3. Dependence of vertical stiffness of sleepers on the passed tonnage when dump cars 6-BC-60 move, 1 - reinforced concrete sleepers; 2 - wooden sleepers.

In equation (2), when the experimentally obtained data on changes in the values of $R_{y}$ and $y_{p}$ were used as arguments, two parameters remain unknown - the coefficient of subgrade reaction of sleepers $C_{y \sigma}\left(\mathrm{kN} / \mathrm{m}^{3}\right)$ and the bending coefficient of sleepers $\alpha$. The bending coefficient of sleepers which is the ratio of the average subsidence of sleepers to the subsidence in the subrail section, in turn, depends on the loads affecting the sleepers, the geometric characteristics of the sleepers, elastic properties of its material, and its coefficient of subgrade reaction.

The values of coefficient $\alpha$ obtained in various studies vary greatly, they were obtained for the conditions of main tracks and are not determined in terms of their applicability - for example, according to the value of the coefficient of subgrade reaction.

Determination of parameters $C_{\sigma}$ and $\alpha$ can be considered as identification of the object of the given structure. Here the mathematical model of the object is given by equation (2) and the method of calculating a sleeper as a variable section beam lying on a solid elastic basis which is characterized by the coefficient of subgrade reaction of the sleeper. The parameters $C_{\sigma}$ and $\alpha$ of this model are selected so that at a given input (the value of the vertical forces $R_{y}$ ), the output of the model only slightly differs from the experimentally defined output.

Searching for unknown parameters in the form of semi-empirical function $\alpha=f\left(C_{\sigma}\right)$ was carried out by one of the hill-climbing methods for the objective function - the coordinate descent method [12]. A value equal to the sum of the squares of relative deviations of the experimental and calculated values of the bends of sleepers in the subrail section was assumed as an objective function:

$$
\varepsilon=\sum_{i=1}^{i=n} \frac{\left(y_{p i}-y_{p 3 i}\right)^{2}}{y_{p i}} ; y_{p i} \neq 0
$$

where $y_{p i}$ - value of bending of the sleeper, determined using the calculation method at $R_{y j},(\mathrm{~m}) ; y_{p \ni i}-$ same, determined experimentally $(\mathrm{m}) ; \mathrm{n}$ - number of experimental points. 
The conducted experiments, statistical processing of the obtained results and the calculations performed according to the stated method using the Mathcad software system allowed to determine the values of the coefficients of subgrade reaction of reinforced concrete and wooden sleepers and their coefficients of bending (Table 1). The values of the mean square deviations of the coefficients of subgrade reaction of reinforced concrete sleepers are within the range of $7 \%$, of wooden sleepers $-13 \%$.

For track sections with axial loads of 201-216 kN, the values of the coefficient of subgrade reaction and the bending coefficients of sleepers are consistent with the data given in $[4,5,8]$.

Table 1. Coefficients of subgrade reaction and bending coefficients of sleepers in the studied section

\begin{tabular}{|c|c|c|c|c|c|c|}
\hline $\begin{array}{c}\text { Section } \\
\text { No. }\end{array}$ & $\begin{array}{c}\text { Sleeper } \\
\text { type }\end{array}$ & $\begin{array}{c}\text { Axial } \\
\text { loading } \\
(\mathrm{kN})\end{array}$ & $\begin{array}{c}\text { Passed tonnage } \\
(\mathrm{mln} \text { tons })\end{array}$ & $\begin{array}{c}\text { Coefficient of } \\
\text { sbgrade reaction } \\
\left(\mathrm{kN} / \mathrm{m}^{3}\right)\end{array}$ & $\begin{array}{c}\text { Mean square } \\
\text { deviations } \\
\left(\mathrm{kN} / \mathrm{m}^{3}\right)\end{array}$ & $\begin{array}{c}\text { Bending } \\
\text { coefficient of } \\
\text { sleeper }\end{array}$ \\
\hline 1 & Wood. I A & 201 & 14 & $7.46 \cdot 10^{4}$ & $0.64 \cdot 10^{4}$ & 0.815 \\
\hline 2 & Wood. I A & 201 & 49 & $8.97 \cdot 10^{4}$ & $0.76 \cdot 10^{4}$ & 0.807 \\
\hline 3 & Wood. I A & 353 & 60 & $14.06 \cdot 10^{4}$ & $1.15 \cdot 10^{4}$ & 0.787 \\
\hline 4 & Wood. I A & 353 & 108 & $15.87 \cdot 10^{4}$ & $1.42 \cdot 10^{4}$ & 0.771 \\
\hline 5 & Wood. I B & 211 & 25 & $7.82 \cdot 10^{4}$ & $0.81 \cdot 10^{4}$ & 0.812 \\
\hline 6 & Wood. I B & 211 & 50 & $8.91 \cdot 10^{4}$ & $0.94 \cdot 10^{4}$ & 0.802 \\
\hline 7 & Wood. I A & 346 & 48 & $13.66 \cdot 10^{4}$ & $1.45 \cdot 10^{4}$ & 0.785 \\
\hline 8 & Wood. I A & 346 & 64 & $13.92 \cdot 10^{4}$ & $1.41 \cdot 10^{4}$ & 0.781 \\
\hline 9 & Wood. I B & 245 & 2 & $6.54 \cdot 10^{4}$ & $0.61 \cdot 10^{4}$ & 0.824 \\
\hline 10 & Wood. I A & 245 & 48 & $8.67 \cdot 10^{4}$ & $0.72 \cdot 10^{4}$ & 0.801 \\
\hline 11 & Wood. I A & 216 & 9 & $6.57 \cdot 10^{4}$ & $0.67 \cdot 10^{4}$ & 0.820 \\
\hline 12 & Wood. I A & 216 & 126 & $10.72 \cdot 10^{4}$ & $1.21 \cdot 10^{4}$ & 0.795 \\
\hline 13 & RC Sh-1 & 353 & 60 & $35.42 \cdot 10^{4}$ & $1.21 \cdot 10^{4}$ & 0.877 \\
\hline 14 & RC Sh-1 & 353 & 108 & $37.64 \cdot 10^{4}$ & $1.25 \cdot 10^{4}$ & 0.868 \\
\hline 15 & RC Sh-1 & 211 & 45 & $21.25 \cdot 10^{4}$ & $0.96 \cdot 10^{4}$ & 0.923 \\
\hline 16 & RC Sh-1 & 211 & 50 & $21.53 \cdot 10^{4}$ & $0.97 \cdot 10^{4}$ & 0.927 \\
\hline 17 & RC Sh-1 & 211 & 50 & $20.14 \cdot 10^{4}$ & $1.12 \cdot 10^{4}$ & 0.934 \\
\hline 18 & RC Sh-1 & 216 & 90 & $24.35 \cdot 10^{4}$ & $1.32 \cdot 10^{4}$ & 0.907 \\
\hline 19 & RC Sh-1 & 216 & 126 & $26.25 \cdot 10^{4}$ & $1.23 \cdot 10^{4}$ & 0.903 \\
\hline 20 & RC Sh-1 & 216 & 180 & $29.43 \cdot 10^{4}$ & $1.75 \cdot 10^{4}$ & 0.897 \\
\hline 21 & RC Sh-1 & 216 & 180 & $29.48 \cdot 10^{4}$ & $1.63 \cdot 10^{4}$ & 0.893 \\
\hline
\end{tabular}

For wooden sleepers the parameters of this dependence are as follows:

$$
C_{\sigma}=K_{o c}\left(6.5 \cdot 10^{4}+0.23 \cdot 10^{4} \cdot T^{0.605}\right)\left(\mathrm{kN} / \mathrm{m}^{3}\right),
$$

where $K_{o c}-1$, if axial loads $<265 \mathrm{kN} ; K_{o c}=1.24$, if loads is $265-294 \mathrm{kN} ; K_{o c}=1.55$, if loads $>294 \mathrm{kN}$.

Semi-empirical dependence of the bending coefficient of sleepers on its coefficient of subgrade reaction has the form:

- for reinforced concrete sleepers: $\alpha=1.2727 \cdot\left(C_{\sigma} \cdot 10^{-4}\right)^{-0.1047}$ (dependence is applicable for the range of the coefficient of subgrade reaction $\left.C_{\sigma}=16.0-43.0 \cdot 10^{-4} \mathrm{kN} / \mathrm{m}^{3}\right)$

- for wooden sleepers: $\alpha=0.9222 \cdot\left(C_{\sigma} \cdot 10^{-4}\right)^{-0.0627}$ (applicable for the range $C_{\sigma}=6.0-22.0 \cdot 10^{-4} \mathrm{kN} / \mathrm{m}^{3}$ )

The works on determining the resistance of reinforced concrete and wooden sleepers to vertical movement, performed in winter conditions in 2012 at sections No. 11, 12, 20 and 21 showed that a 1.6 times increase in the coefficient of subgrade reaction for wooden sleepers and 1.8 times increase for reinforced concrete sleepers in winter for the Ukrainian industrial railways is substantiated. 


\section{Conclusions}

1. On the basis of conducted experiments, the values of coefficients of subgrade reaction of reinforced concrete and wooden sleepers with axial loads of up to 35 tons per axle have been obtained. The dependence of the change of these parameters in the course of the operation of the track has been established taking into account the level of axial loads.

2. The obtained information will be used in further studies of interaction dynamics of the track of main railways with the rolling stock with axial loads of 30-35 tons per axle which will give an opportunity to provide substantiated recommendations concerning the norms of the arrangement and maintenance of the track in such conditions.

\section{References}

1. O.M. Darenskiy Theoretical and experimental studies of the performance of railway tracks of industrial transport - monograph, (Kharkiv: UkrSART, 2011)

2. V.P. Novichkov Rational Methods of Strengthening the Railway Track, (Zh. D. Transp., 1956)

3. F. Birmann, Eisenbahntechnische Rundschau, 7, 229-246 (1977)

4. N.V. Ivolga, V.I. Klimov, Proceedings of DIIT, 167, 73-81 (1975)

5. V.G. Albrekht, A.F. Zolotarsky, Modern designs of the upper railway structure (Transport, 1975)

6. A.F. Zolotarsky, B.A. Evdokimov, L.G. Isaev, L.G. Krysanov Reinforced concrete sleepers for railways (Transport, 1980)

7. E.I. Danilenko, V.V. Rybkin, Rules for durability and stability calculation of the railway track, (Transport of Ukraine, 2006)

8. O.P. Ershkov, Proceedings of the Central Research Institute of the MPS, 264, 39-48 (1964)

9. V.F. Yakovlev, I.I. Semenov, V.I. Abrosimov, Proceedings of the LIIZhT, 326, 66-85 (1971)

10. M.A. Frishman, L.Ya. Vorobeichik, R.S. Lipovskoy, Bulletin of the Central Research Institute of the Ministry of Transport, 8, 31-35 (1970)

11. E. S. Varyzgin, Contents of the ballast prism of the railway track, (Transport, 1978)

12. O.M. Darenskiy, N.V. Bugaets, V.G. Vitolberg, Collection of sciences works of UkrDazt, 109, 222-231 (2009) 